\title{
Assessing the genetic variation of $T y-1$ and $T y-3$ alleles conferring resistance to tomato yellow leaf curl virus in a broad tomato germplasm
}

\author{
Myluska Caro • Maarten G. Verlaan • Olga Julián • Richard Finkers • \\ Anne-Marie A. Wolters · Samuel F. Hutton · John W. Scott • Richard Kormelink • \\ Richard G. F. Visser · Maria J. Díez • Ana Pérez-de-Castro · Yuling Bai
}

Received: 20 June 2014/ Accepted: 13 May 2015/Published online: 26 May 2015

(C) The Author(s) 2015. This article is published with open access at Springerlink.com

\begin{abstract}
Tomato yellow leaf curl virus (TYLCV) hampers tomato production worldwide. Our previous studies have focussed on mapping and ultimately cloning of the TYLCV resistance genes $T y-1$ and $T y-3$. Both genes are derived from Solanum chilense and were shown to be allelic. They code for an RNAdependent RNA polymerase (RDR) belonging to the RDR $\gamma$ type defined by a DFDGD catalytic domain. In this study, we first fine-mapped the TYLCV resistance in S. chilense LA1932, LA1960 and LA1971. Results
\end{abstract}

Myluska Caro, Maarten G. Verlaan and Olga Julián with equal contribution.

Electronic supplementary material The online version of this article (doi:10.1007/s11032-015-0329-y) contains supplementary material, which is available to authorized users.

M. Caro - M. G. Verlaan - R. Finkers .

A.-M. A. Wolters · R. G. F. Visser · Y. Bai $(\bowtie)$

Wageningen UR Plant Breeding, Wageningen University

and Research Centre, Droevendaalsesteeg 1,

6708 PB Wageningen, The Netherlands

e-mail: bai.yuling@wur.nl

M. Caro

Graduate School Experimental Plant Sciences,

Wageningen University and Research Centre,

Droevendaalsesteeg 1, 6708 PB Wageningen, The

Netherlands

Present Address:

M. G. Verlaan

Rijk Zwaan Breeding B.V., Burgemeester Crezéélaan 40,

2678 KX De Lier, The Netherlands showed that chromosomal intervals of the causal genes in these TYLCV-resistant accessions overlap and cover the region where $T y-1 / T y-3$ is located. Further, virus-induced gene silencing was used to silence $T y-1 / T y-3$ in tomato lines carrying TYLCV resistance introgressed from $S$. chilense LA1932, LA1938 and LA1971. Results showed that silencing Ty-1/Ty-3 compromised the resistance in lines derived from S. chilense LA1932 and LA1938. The LA1971derived material remained resistant upon silencing $T y$ $1 / T y-3$. Further, we studied the allelic variation of the $T y-1 / T y-3$ gene by examining cDNA sequences from nine $S$. chilense-derived lines/accessions and more than 80 tomato cultivars, landraces and accessions of related wild species. The DFDGD catalytic domain of the $T y-1 / T y-3$ gene is conserved among all tomato

O. Julián · M. J. Díez · A. Pérez-de-Castro Instituto Universitario de Conservación y Mejora de la Agrodiversidad Valenciana (COMAV) (University Institute for Conservation and Improvement of Agrobiodiversity), Ciudad Politécnica de la Innovación (CPI), Universitat Politècnica de València, Camino de Vera, s/n Edificio 8E escalera J, 46022 Valencia, Spain

S. F. Hutton - J. W. Scott

Gulf Coast Research and Education Center, University of Florida, 14625 CR 672, Wimauma, FL 33598, USA

R. Kormelink

Laboratory of Virology, Wageningen University and

Research Centre, Droevendaalsesteeg 1,

6708 PB Wageningen, The Netherlands 
lines and species analysed. In addition, the 12 base pair insertion at the 5-prime part of the $T y-1 / T y-3$ gene was found not to be specific for the TYLCV resistance allele. However, compared with the susceptible ty-1 allele, the $T y-1 / T y-3$ allele is characterized by three specific amino acids shared by seven TYLCV-resistant $S$. chilense accessions or derived lines. Thus, $T y-1 /$ Ty-3-specific markers can be developed based on these polymorphisms. Elevated transcript levels were observed for all tested $S$. chilense RDR alleles (both $T y-1$ and $t y-1$ alleles), demonstrating that elevated expression level is not a good selection criterion for a functional $T y-1 / T y-3$ allele.

Keywords Breeding $\cdot$ Resistance $\cdot$ RNA-dependent RNA polymerase (RDR) · Tomato $\cdot$ Tomato yellow leaf curl virus (TYLCV) · Virus-induced gene silencing (VIGS)

\section{Introduction}

Tomato yellow leaf curl virus (TYLCV), a begomovirus of the geminiviridae family, is a phloem-limited singlestranded DNA virus that is vectored by the whitefly (Bemisia tabaci). TYLCV is one of the causal viruses of tomato yellow leaf curl disease (TYLCD). In the last two decades, TYLCD has been a major constraint on tomato (Solanum lycopersicum) production in many warm and (sub) tropical regions worldwide, and nowadays, it is still a huge problem for many farmers. Tomato plants affected by TYLCD show yellowing and curling of apical leaves, and when plants are severely affected, flowers are abscised and plants stop growing completely (Cohen and Lapidot 2007). Controlling vector whitefly populations is expensive, labour intensive, and often ineffective; thus, using resistant tomato cultivars is a good solution to control TYLCV. No resistance has yet been described in cultivated tomato, and breeders have screened wild tomato relatives to identify resistance sources from which resistance loci have been introgressed (Ji et al. 2007; Vidavski 2007). To date, six TYLCV resistance/tolerance genes have been described, Ty-1 to Ty-6 (Figure S1) (Zamir et al. 1994; Hanson et al. 2006; Ji et al. 2007; Anbinder et al. 2009; Ji et al. 2009; Hutton et al. 2012; Hutton and Scott 2013). Most of these loci originated from accessions of Solanum chilense. The $T y-1$ gene is derived from
LA1969 and the $T y-3$ gene from LA2779. Both $T y-1$ and Ty-3 are located on the long arm of tomato chromosome 6 and have been shown to be allelic (Verlaan et al. 2011, 2013). LA1932 is reported to carry an allele at this locus, Ty-3a, (Scott et al. 1996; Ji et al. 2007) and is also the donor of $T y-4$, which maps to chromosome 3 (Ji et al. 2009). Ty-6 is derived from LA2779 (also the donor of the $T y-3$ allele) and recently mapped to chromosome 10 (Hutton and Scott 2013). The other two known TYLCV resistance genes do not originate from $S$. chilense. $T y-2$ was introgressed from $S$. habrochaites $f$. glabratum accession "B6013" and is located on chromosome 11 (Yang et al. 2014). Ty-5 was first described in TY172, a breeding line said to be derived from crosses of four $S$. peruvianum accessions. However, whether the $T y-5$ originated from $S$. peruvianum is still in debate; there is recent evidence that this gene is recessively inherited and resulted from a loss-of-function mutation that likely occurred in cultivated tomato (Hutton et al. 2012; Levin et al. 2013). Ty-5 maps on chromosome 4 , and because of its recessive nature, the symbol ty-5 was proposed to refer to this gene (Hutton et al. 2012).

Recently, we cloned the $T y-1$ and $T y-3$ genes (Verlaan et al. 2013), which code for RNA-dependent RNA polymerases (RDR) belonging to the RDR $\gamma$ type. RDRs are defined by a conserved catalytic domain, DFDGD for the RDR $\gamma$, and DLDGD for the RDR $\alpha$ type. In Arabidopsis thaliana, the RDR $\alpha$ type has been well studied and shown to be involved in stress responses, pathogen resistance, female gamete formation, and transgene silencing among many other functions (excellently reviewed in Willmann et al. 2011). In contrast to the RDR $\alpha$ type, no functions for $\operatorname{RDR} \gamma$ have been described in literature. Because the $\mathrm{RDR} \alpha$ type is known to be involved in the amplification of the siRNA signal, it is possible that the RDR $\gamma$ type has a similar function in siRNA amplification. Our results suggested that $T y-1$, representative for the $\operatorname{RDR} \gamma$ type and a novel class of $R$-genes, confers resistance through enhanced transcriptional gene silencing (Butterbach et al. 2014).

In $S$. chilense, multiple accessions have been described as symptomless after TYLCV inoculation. For some accessions, including LA1960, LA1971 and LA1938, the causal genes for resistance were mapped to chromosome 6 in the chromosome region where $T y$ 1 is located, suggesting allelism to $T y-1 / T y$ - 3 (Pérez de Castro et al. 2013; Agrama and Scott 2006, Hutton and Scott, unpublished data). For other accessions, the 
Table 1 Information on progenies derived from S. chilense accessions LA1932, LA1960 and LA1971

\begin{tabular}{|c|c|c|c|c|c|c|c|c|c|}
\hline \multirow[t]{2}{*}{ Family $^{\mathrm{a}}$} & \multirow[t]{2}{*}{ Susceptible parent } & \multirow[t]{2}{*}{ Resistant parent ${ }^{\mathrm{b}}$} & \multirow[t]{2}{*}{ Solanum chilense accession } & \multicolumn{6}{|c|}{$\begin{array}{l}\text { Number of plants per genotype used in the disease } \\
\text { test }^{c}\end{array}$} \\
\hline & & & & $\mathrm{P}_{1}$ & $\mathrm{P}_{2}$ & $\mathrm{~F}_{1}$ & $\mathrm{~F}_{2}$ & $\mathrm{BC}_{1 \mathrm{~S}}$ & $\mathrm{BC}_{1 \mathrm{R}}$ \\
\hline 1 & Fortuna $\mathrm{C}$ & $\left(\mathrm{FC} \times \mathrm{BC}_{1} \mathrm{~S}_{4}\right) \mathrm{S}_{2}$ & LA 1932 & 25 & 23 & & 155 & & \\
\hline 2 & Fortuna $\mathrm{C}$ & $\left(\mathrm{FC} \times \mathrm{BC}_{1} \mathrm{~S}_{4}\right) \mathrm{S}_{2}$ & & 25 & 18 & & 113 & & \\
\hline 3 & Fortuna $\mathrm{C}$ & $\mathrm{BC}_{1} \mathrm{~S}_{4}$ & LA 1960 & 25 & 9 & & 155 & & \\
\hline 4 & Fortuna $\mathrm{C}$ & $\mathrm{BC}_{1} \mathrm{~S}_{4}$ & LA 1971 & 25 & 0 & & 116 & & \\
\hline 5 & Fortuna $\mathrm{C}$ & $\mathrm{BC}_{1} \mathrm{~S}_{4}$ & & 25 & 8 & 9 & 143 & 89 & 73 \\
\hline
\end{tabular}

${ }^{a}$ Families 1 and 2, as well as 4 and 5 were derived from different plants of the same population

b FC: susceptible parent; BC: backcross generation with selection; S: selfing generation with selection (see Fig. 1 for details). Subscript numbers after $\mathrm{BC}$ and $\mathrm{S}$ indicate generations

c $\mathrm{P}_{1}$ : susceptible parent; $\mathrm{P}_{2}$ : resistant parent; $\mathrm{BC}_{1 \mathrm{~S}}$ : backcross to the susceptible parent; $\mathrm{BC}_{1 \mathrm{R}}$ : backcross to the resistant parent

causal genes have not been mapped (Pico et al. 1999). Thus, it is intriguing whether the TYLCV resistance in various $S$. chilense accessions is governed by allelic variants of the $T y-1 / T y-3$ gene.

The aim of this study was to explore the allelic variation of $T y-1 / T y-3$ in wild tomato relatives, with the focus on $S$. chilense accessions. In a previous study, we showed that the susceptible $t y-1$ allele differs from the resistant $T y-1 / T y-3$ allele at multiple amino acid positions (Verlaan et al. 2013). The most striking difference was a 4 amino acid insertion near the start of the protein in the $T y-1 / T y-3$ allele, while in the catalytic domain, there were no differences. In this study, we compare the full-length cDNA sequence of seven different tomato introgression lines that have $S$. chilense-derived TYLCV resistance and two $S$. chilense accessions to identify $T y-1 / T y$-3-specific polymorphisms. The insertion and catalytic domain of the protein are also explored in 87 lines/accessions of tomato and its wild relatives to see whether these $S$. chilense features are unique. Further, we silenced the alleles of the $T y-1 / T y-3$ gene in several TYLCV-resistant tomato lines carrying introgressions from different $S$. chilense accessions to check whether the silencing compromises the TYLCV resistance in these lines.

\section{Results}

Potential allelic variants in multiple $S$. chilense accessions

In a previous study, TYLCV resistance in S. chilense accessions LA1932, LA1960 and LA1971 was studied and shown to be controlled by a major dominant gene located on chromosome 6 (Pérez de Castro et al. 2013), indicating that the causal genes in these accessions are likely allelic to $T y-1$. To further verify the localization of the causal genes in the $T y-1$ interval, fine-mapping was performed in this study using $\mathrm{F}_{2}$ and backcross mapping populations derived from these three accessions (Table 1, Figure S2). Markers covering the $T y-1$ region between markers C2_At3g46780 and M-M005H10 on chromosome 6 were applied to genotype recombinants identified between these two markers (Fig. 1, Table S1 and S2). Of 844 plants from these populations, 66 recombinants were obtained and

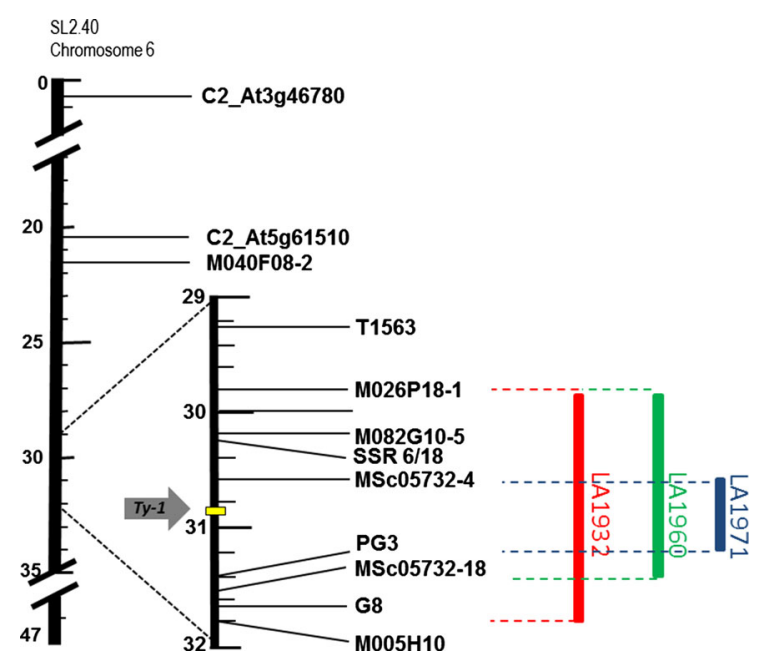

Fig. 1 Schematic physical map of the $T y-1$ region showing locations of resistance loci in Solanum chilense LA1932, LA1960 and LA1971. Numbers represent millions of basepairs. Position of markers is based on BLAST results on the tomato WGS 2.40 chromosomes database 
tested for TYLCV resistance (Table S1). In Families 1 and 2 that are derived from LA1932, 22 recombinants were found. The most informative recombinants are no. 6, 17 and 18 (Table 2, Table S1). These three recombinants showed clear TYLCV symptoms (Figure S3), indicating that the TYLCV resistance locus from LA1932 is located between markers M-M026P18 and G8 since all three lacked any $S$. chilense introgression within this interval, but each had such an introgression on one or the other side of the interval. In a similar way, the resistance loci in LA1960 and LA1971 were defined. In the Family 3 derived from LA1960, two informative recombinants, i.e. 7 and 10 , showed that the locus is bordered by markers M-M026P18 and MSc05732-18 (Table 2, Table S1). Families 4 and 5 (both derived from LA1971) produced three highly informative recombinants, 13, 21 and 22, which placed the LA1971 resistance locus between markers MSc05732-4 and PG3 (Table 2, Table S1). All three chromosomal intervals of the analysed families overlap and cover the $T y-1 / T y-3$ locus (Fig. 1).

For the resistance in LA1938, breeding practice showed that there is a linkage of the resistance from LA1938 with the self-pruning $(s p)$ locus, which is located on the long arm of chromosome 6 (Agrama and Scott 2006). Suppression of recombination made breakage of this linkage difficult. Using an $\mathrm{F}_{2}$ of the cross between LA1938-derived line F11E976-BK (also known as Fla.976) and a susceptible tomato cultivar, the resistance was shown to be linked with the Ty-3-associated markers used in Ji et al. (2007).

Ty-1/Ty-3 alleles in multiple $S$. chilense-derived introgression lines

To assess whether TYLCV resistance derived from the above studied $S$. chilense accessions was based on $T y$ 1/Ty-3 alleles, a VIGS approach was applied to silence the $T y-1$ gene with the TRV2-180 and/or TRV2-190 silencing constructs as described in Verlaan et al. (2013). Tomato introgression lines derived from these accessions were used for VIGS (Table 3). Tomato Moneymaker (MM) plants were used as a susceptible control. Two weeks after TYLCV inoculation, all MM plants showed typical TYLCV symptoms, while plants of tomato introgression lines infiltrated with the empty vector $(\mathrm{EV})$ remained symptom free (Figure S3). In the lines derived from S. chilense LA1932 and

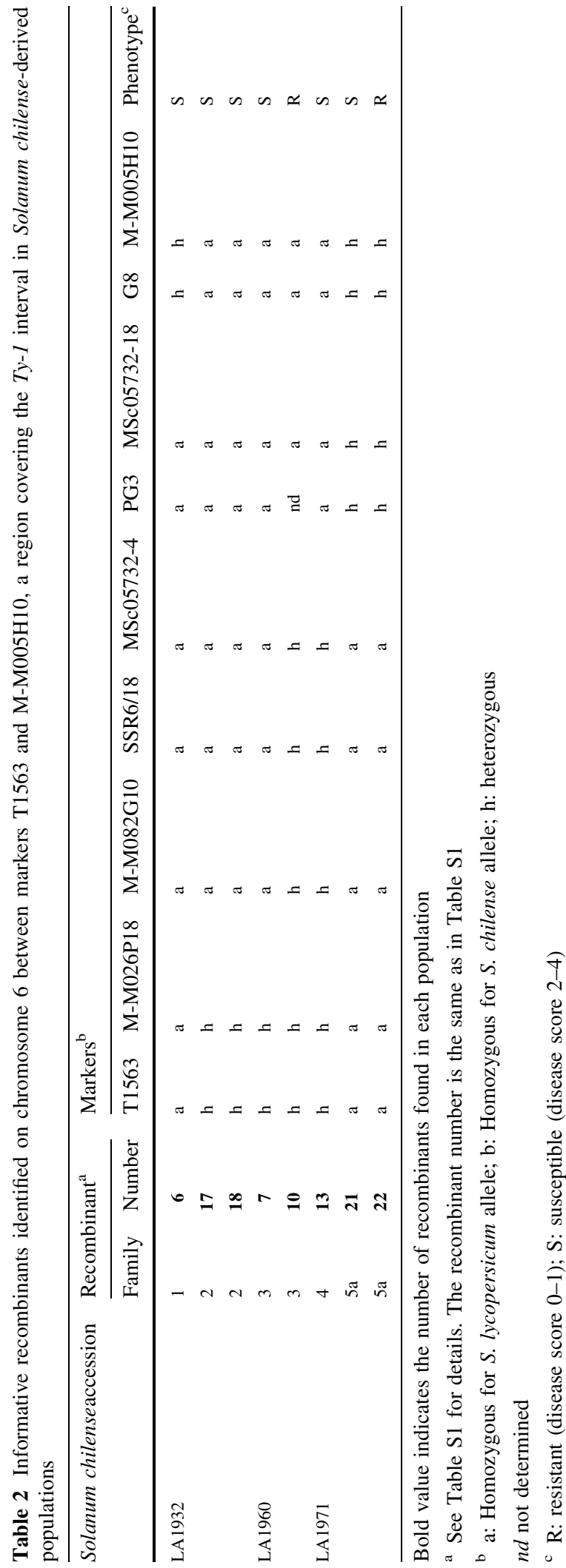




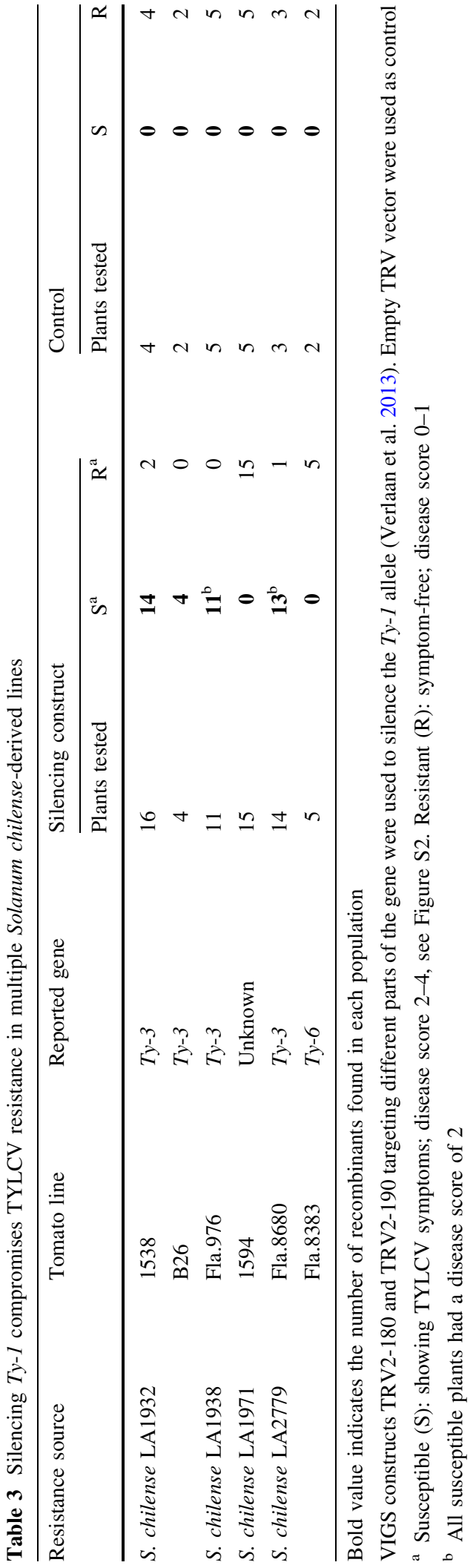

LA1938, all but two out of 31 plants infiltrated with TRV2-180/190 silencing constructs showed typical symptoms (Table 3). The two symptom-free plants may have been escaped from the TYLCV infection or due to a low silencing level. Together with the mapping data (Fig. 1), the collapse of TYLCV resistance by VIGS clearly indicates that resistance in the tested lines derived from S. chilense LA1932 and LA1938 is based on Ty-1/Ty-3.

In contrast, plants of line 1594 with TYLCV resistance derived from LA1971 remained symptomless after infiltration with both TRV2-180 and TRV2190 silencing constructs (Table 3). Since all PDS control plants of this line were showing photo bleaching, we assumed that VIGS was working in this line as well. Thus, we expected the majority of the TRV silencing construct-infiltrated plants of the line 1594 to become susceptible if the resistance in this line is conferred by a $T y-1$ allelic variant. Two lines derived from S. chilense LA2779 were included in the VIGS experiment. In the line Fla. 8680, which carries the $T y$ 3 allele (Verlaan et al. 2013), all TRV silencing construct-infiltrated plants except for one showed TYLCV symptoms. But resistance was uncompromised in Fla. 8383, which carries the Ty-6 allele (Hutton and Scott 2013), indicating that Ty-6 is different from the $T y-1 / T y-3$ gene. For each line, at least two VIGS experiments were performed with comparable results.

Genetic variation of the RDR in tomato and its wild relatives

There is a four amino acid insertion, from positions 12 to 16, present in the Ty-1/Ty-3 alleles (Verlaan et al. 2013) compared with the MM allele. To determine whether this insertion may be present in a variety of $S$. chilense-derived TYLCV-resistant lines, cDNA was made from six $S$. chilense-derived lines containing $T y$ 1/Ty-3 and two wild $S$. chilense accessions (Figure S4A). Primers were designed to amplify the region of interest, and sequence analysis showed that these four amino acids (Proline, Serine, Cysteine, Isoleucine) are present in all lines. However, there is one synonymous SNP (T-G) among the S. chilense-derived lines (Figure S4A).

To check for the presence/absence of the four amino acid insertion among cultivated tomato and wild tomato species, the re-sequenced genome reads 

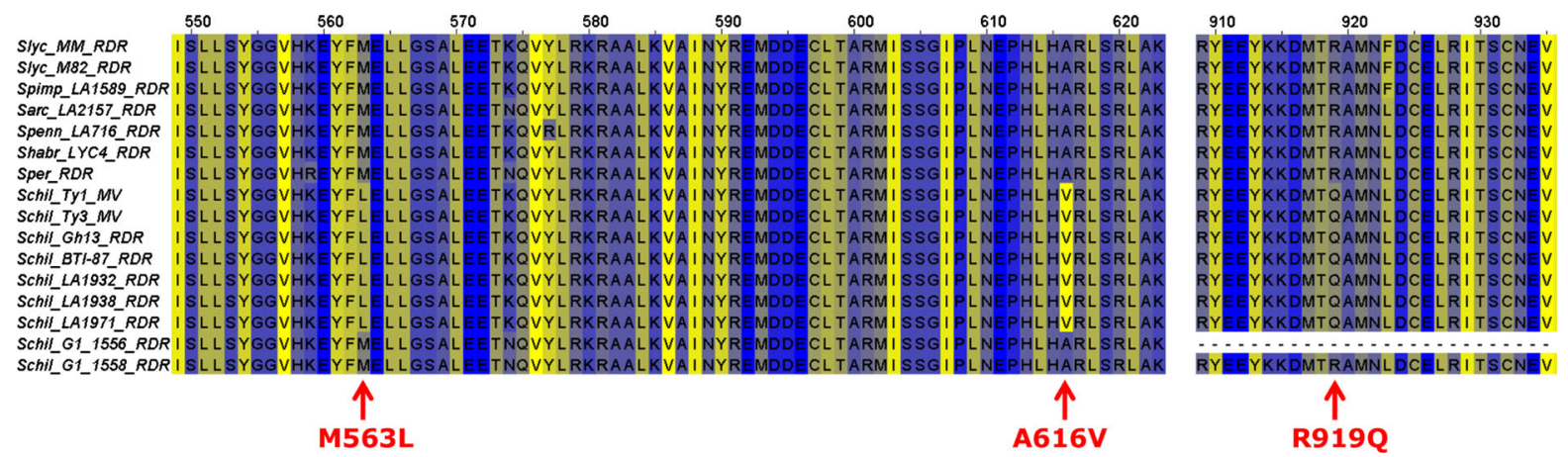

Fig. $2 T y-1 / T y-3$ allele-specific polymorphisms. Partial alignment of protein sequences of the Ty-1 RDR alleles; red arrows indicate three $T y-1 / T y$-3-specific amino acids

of 84 accessions of different species were mapped to the reference genome of $S$. lycopersicum cv. Heinz 1706 and compared for the insertion. In addition, draft de novo assemblies of three tomato wild relatives $(S$. arcanum LA2157, S. habrochaites LYC4 and S. pennellii LA716) were included in the analysis (Figure S4B). All cultivated tomato lines in the test panel (including S. lycopersicum var. lycopersicum and $S$. lycopersicum var. cerasiforme) and the majority of the wild species do not have the insertion (Figure S4C). Several related wild species in the test panel do, however, have the insertion, i.e. S. arcanum LA2157, S. corneliomulleri LA118, S. peruvianum LA1954, two accessions of $S$. huaylasense (LA1983 \& LA1365), S. habrochaites LYC4, and S. pennellii LA716 (Figure S4B \& S4D). Within the 12-bp insertion, one non-synonymous SNP was detected in S. habrochaites LYC4, leading to an amino acid change $(\mathrm{P} \rightarrow \mathrm{S})$. In many disease tests (data not shown), S. arcanum LA2157 and S. habrochaites LYC4 exhibited clear virus symptoms after TYLCV infection.

To further explore crucial $T y-1 / T y-3$ allele-specific polymorphisms, the sequences of the coding regions of the RDR from tomato, nine $S$. chilense-derived lines and five wild tomato accessions were obtained and analysed (Figure S6). Within S. chilense, all genotypes have different $R D R$ alleles, as shown by the presence of accession-specific SNPs or combination of SNPs. Importantly, five SNPs (two in exon 12, one each in exon 13, 14 and 18, yellow marked in Figure S6) specific to the $T y-1 / T y-3$ alleles were identified. Additionally, four SNPs (two in exon 2, two in exon 6 , green marked in Figure S6) were found to be unique for the $T y-3$ allele. The $R D R$ cDNA sequence of $S$. chilense G1.1556 contained intron 17, which would result in a premature stop codon. No full-length cDNA sequence was obtained from S. chilense LA2779derived line Fla.8383, but the sequence of exons 12-14 was identical to the MM sequence, indicating the presence of a susceptible $R D R$ allele.

RDR protein sequences were derived from the cDNA sequences and aligned (Figure S7). A small number of $T y$-1/Ty-3-specific amino acids were observed, which were shared by TYLCV-resistant $S$. chilense accessions LA1969 (Ty-1), LA2779 (Ty-3), LA1932 (Ty-3A), LA1938, LA1971, and introgression lines BTI-87 and Gh13 reported to contain Ty-3 alleles (Menda et al. 2014; Mejía et al. 2005). These amino acids are L563, V616, and Q919 (numbering based on the $T y-1$ allele, SEQ2 in Patent No. WO2012125025). They are absent in S. chilense accessions G1.1556 and G1.1558 that do not contain $T y-1$ or $T y-3$ (Fig. 2). A phylogenetic analysis using an unrooted tree grouped together the proteins of seven $S$. chilense $T y-1 / T y-3$ alleles responsible for TYLCV resistance (Fig. 3).

The catalytic domain of the $T y-1$ gene is conserved in tomato and its wild relatives

The catalytic domain of the $T y-1 / T y-3$ allele is characterized by a five amino acid motif, DFDGD (position 723-727) (Verlaan et al. 2013). SNPs in this domain could potentially have an effect on the functioning of this protein. Sequence analysis of an amplified cDNA fragment among all tested S. chilensederived lines showed that there were no SNPs present in the catalytic domain, and furthermore, no 


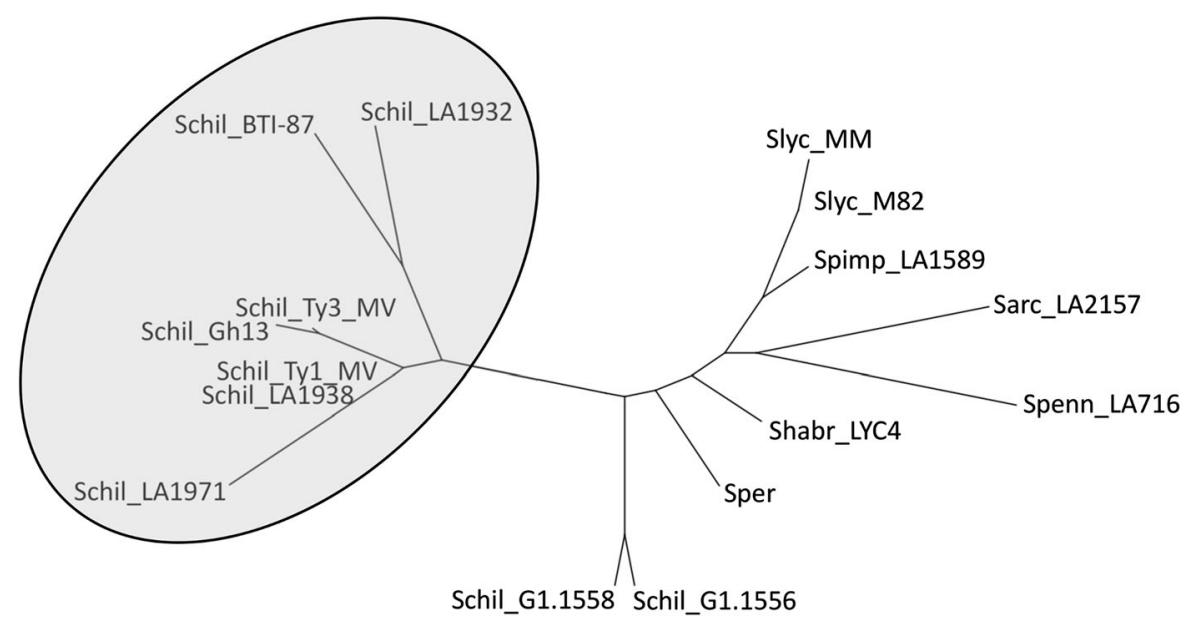

0.01

Fig. 3 Unrooted phylogenetic tree of protein sequences of $T y-1 / T y-3$ RDR of accessions of $S$. chilense and other (wild) tomato species. The RDR proteins of the TYLCV-resistant $S$. chilense accessions cluster in one clade, as indicated

differences were found in four amino acids up- or downstream of the catalytic domain (Figure S5). The sequence coding for the catalytic DFDGD motif was also compared among all available sequences used for Figure S4. This region was found to be highly conserved, and no polymorphisms were detected among the susceptible and resistant lines analysed.

Elevated expression level of the $R D R$ alleles in $S$. chilense accessions

Analysis of expression of the $R D R$ in $S$. chilensederived resistant lines revealed significant differences compared with the tomato susceptible allele. The expression level of the alleles was measured at different time points in the presence or absence of the virus (Figure S8). Six resistant lines derived from S. chilense LA1969, LA2779, LA1932, LA1938 and LA1971 showed significantly higher relative expression of $R D R$ compared with the susceptible allele, despite the presence of the virus. $R D R$ transcript levels of line Fla.8383, derived from S. chilense LA2779, remained very low, resembling the expression levels of the ty- 1 allele from cultivated tomato. This is in agreement with the result that Fla.8383 carries a susceptible $R D R$ allele and the TYLCV resistance in this line is conferred by another gene located on chromosome $10(T y-6)$. Similarly, transcript levels of the accessions $S$. arcanum LA2157, S. habrochaites LYC4 and S. pennellii LA716 were comparable with those of the susceptible allele.

However, two accessions of S. chilense (G1.1556 and G1.1558) with resistance governed by genes of recessive nature (data not shown) also showed a significantly higher level of expression of the $R D R$ compared with MM. These results suggest that even though a high expression of the $R D R$ is necessary for the $T y-1 / T y$-3-mediated resistance, it is not exclusively responsible of the resistant response.

\section{Discussion}

Recently, we cloned the $S$. chilense-derived TYLCV resistance genes $T y-1$ and $T y-3$ and found that they are allelic and code for an RDR of the DFDGD class (Verlaan et al. 2013). In this study, we show, based on fine-mapping and/or VIGS, that functional Ty-1/Ty-3like alleles are present in $S$. chilense accessions LA1932, LA1938 and likely also in LA1960 and LA1971. We also show that the catalytic domain of the Ty- 1 gene is conserved among cultivated tomato and several wild species in the tomato clade. Three $T y-1 /$ Ty-3-specific amino acids were identified among TYLCV-resistant $S$. chilense accessions, each genotype representing different $R D R$ alleles. These specific 
amino acids in concomitance with high gene expression level are indicative of $T y-1 / T y-3$-mediated resistance. An insertion of 12 base pairs at the 5-prime part of the coding sequence is, however, found in $S$. chilense-derived alleles and also in several other wild Solanum species of which some are known to be susceptible to TYLCV.

One $S$. chilense accession can harbour more than one TYLCV resistance gene

Many S. chilense accessions, including LA1969, LA1932, LA1938, LA2779, LA1960 and LA1971, are resistant to TYLCV. The resistant $T y-1$ and $T y-3$ alleles were originally identified in LA1969 and LA2779, respectively. The combined data from genetic mapping and VIGS showed the existence of $T y-1 /$ Ty-3 allelic variants, which control TYLCV resistance in LA1932 and LA1938. Our mapping results showed that the gene controlling the TYLCV resistance in LA1971 is also located in the same region of $T y-1 / T y-3$ (Fig. 1); therefore, it was expected that LA1971 harbours a $T y-1 / T y-3$ allele. However, this hypothesis was not confirmed by the VIGS experiments, since silencing the $T y-1 / T y-3$ gene did not compromise the resistance in line 1594 derived from LA1971. Expression analysis of the $R D R$ in this line showed the highest transcript levels among all the resistant lines tested, about 80 times higher compared with the susceptible ty-1 allele levels (Figure S8). Complete suppression of VIGS-targeted genes in tomato is rarely observed (Sahu et al. 2012); thus, the inability of this silencing approach to repress such high expression levels might have caused the unexpected resistant phenotype. An alternative possibility is that line 1594 may carry, in addition to a $T y-1$ allele, another TYLCV resistance gene derived from LA1971. It is worthwhile to note that the LA1971-derived parental line of our mapping population and line 1594 used in the VIGS experiments in this study are different, but "sisters" of the lines described in the previous paper of Pérez de Castro et al. (2013). Checking the LA1971 introgressions in this line, it appeared that line 1594 has multiple introgressions located on chromosomes 6, 7, 10 and 11 (see Fig. 2 in Pérez de Castro et al. 2013). Interestingly, the introgressions on chromosome 10 and 11 overlap with the intervals where $T y-6$ derived from $S$. chilense LA2779 (Hutton and Scott 2013) and Ty-2 from $S$. habrochaites B6013 (Yang et al. 2014) are mapped, respectively. Therefore, the presence of a second resistance gene could explain why line 1594, with $S$. chilense LA1971-derived resistance, remained symptomless after silencing of $T y-1 / T y-3$ followed by TYLCV inoculation. Similarly, a resistant response after silencing the $R D R$ allele in the $S$. chilense LA2779-derived line Fla.8383 was observed. Sequence analysis revealed that this line does not contain the $T y-1 / T y$-3-resistant allele-specific polymorphisms, and transcript levels of the $R D R$ in this line resemble those of the susceptible ty-1 allele (Figure S8). As Fla.8383 is devoid of a functional $T y-1 / T y-3$ allele, the TYLCV resistance in this line is probably conferred by $T y-6$. We are further genotyping these lines to verify our hypothesis. Alternatively, a mapping approach on populations segregating for only one introgression would be helpful in solving the puzzle. Future cloning of $T y-2$ and $T y-6$ would allow silencing of these two genes in lines 1594 and Fla.8383 to confirm this hypothesis.

The wild tomato species $S$. chilense is self-incompatible and thus heterogeneous, leading to multiple alleles of the same gene present in one accession (Bai et al. 2004). As shown in LA1932, resistant alleles of both $T y-1 / T y-3$ and $T y-4$ are present (Ji et al. 2009). Also in LA2779, both $T y-3$ and $T y-6$ have been identified. Similarly, LA1971 may carry alleles of $T y$ 1/Ty-3 and other $T y$-genes, e.g. Ty-6. Thus, depending on selection procedures and heterogeneity present in $S$. chilense, it is possible that advanced S. chilensederived lines carry different resistance genes for TYLCV resistance. Pyramiding of different $T y$-genes could possibly provide higher resistance levels and/or broaden the resistance to a wider range of begomoviruses. Therefore, when a species is shown to be resistant to multiple viruses, it is possible-even probable - that more than one gene is contributing to the broad-spectrum resistance. For example, the accession S. chilense LA1932 was found to be resistant to Tomato mottle virus (ToMoV) and TYLCV (Ji et al. 2009; Scott et al. 1996). It is worthwhile to test whether $T y-1$ or $T y-4$ confers resistance to both viruses. These genes should be studied more deeply in order to understand their specificity and effectiveness.

It is unfortunate that we did not have enough seeds of an advanced introgression line derived from the accession LA1960 for VIGS. The mapping data showed that a $T y-1$ allele is likely present in this accession. However, we cannot rule out the possibility 
of the presence of other $T y$-genes in accession LA1960. As shown in Pérez de Castro et al. (2013), the introgression line generated by selecting for TYLCV resistance carries multiple LA1960 fragments, including the $T y-1$ region on chromosome 6 and the $T y-6$ region on chromosome 10 .

Ty-1/Ty-3-mediated resistance is determined by allele-specific polymorphisms in concomitance with high expression levels of the $R D R$

In our previous study (Verlaan et al. 2013), we detected a 12 base pairs insertion in the 5 prime part of the coding sequence in the resistant $T y-1 / T y-3$ allele and proposed this polymorphism as the most striking difference between the $T y-1 / T y-3$ and $t y-1$ alleles. Here we show that this 12 base pairs insertion is present in a set of 8 lines/accessions containing different $S$. chilense alleles as well as in the related wild species $S$. arcanum, S. corneliomulleri, S. peruvianum, S. huaylasense, S. habrochaites and S. pennellii, evidencing that this feature is not $S$. chilense specific. Since some of these species, e.g. S. arcanum LA2157 and $S$. habrochaites LYC4 have exhibited virus symptoms after TYLCV infection (data not shown), we conclude that this insertion cannot be used as a $T y-1 / T y-3-$ specific marker. By further analysing the $R D R$ coding regions, we succeeded in finding five SNPs present in different exons that are specific to the $T y-1 / T y-3$ allele. These SNPs can be exploited to generate in-gene markers. Further, four SNPs were shown to be unique to $T y$-3, useful for allele-specific marker development. In addition, the origin of the $T y-1 / T y-3$ alleles can be traced by accession-specific SNPs (Figure S6).

In a previous study, we found that the resistant $T y-1$ allele was more highly expressed than the susceptible ty- 1 allele (Verlaan et al. 2013). In this study, we observed comparable results where the expression of all $T y-1 / T y$-3-resistant alleles is significantly higher than the susceptible allele. However, the expression level varied among different $R D R$ alleles (Figure S8). Surprisingly, elevated expression levels of the $R D R$ were also detected in S. chilense accessions G1.1556 and G1.1558, which carry a susceptible ty- 1 allele. Therefore, we conclude that the expression level of the $R D R$ is not solely responsible for the resistance, but this feature together with the $T y-1 / T y-3$ allele-specific amino acid sequence determines the resistance response.
The same set of tomato accessions/lines was also used to compare the typical DFDGD catalytic domain of the RDR $\gamma$ type to which the $T y-1$ gene belongs. No SNPs were found in the domain nor in 12 base pairs upor downstream of this domain. Further, no differences were found among a $T y-2$ carrying line, a wild $S$. pimpinellifolium and the same nine $S$. chilense-derived lines described before. The region was also compared among the same set of cultivated lines and wild tomato accessions. It was found that the catalytic domain was conserved, and no SNPs were found in any of the accessions/lines tested. This could indicate that this gene is important for the plant and that SNPs in the catalytic domain have a negative effect on plant fitness.

\section{Conclusion}

In conclusion, this study shows that probably many $S$. chilense accessions carry a TYLCV resistance locus on chromosome 6 , allelic to $T y-1 / T y$-3. Fine-mapping and/or more VIGS experiments could prove whether this is really true. The catalytic domain of the $T y-1 / T y$ 3 gene is conserved among Solanum species. The 12 base pair insertion in $T y-1 / T y-3$ is present in $S$. chilense and in six other wild Solanum species, and not exclusively linked to TYLCV resistance. To develop allele-specific markers, SNPs unique to the resistant $T y-1 / T y-3$ alleles can be used. Moreover, our study shows that (1) VIGS can be applied as a tool for testing allelism, and (2) more than one TYLCV resistance gene can be present in one $S$. chilense accession.

\section{Materials and methods}

Plant materials

In Spain, four breeding lines (two derived from $S$. chilense LA1932, one from S. chilense LA1960, and one from S. chilense LA1971) were selected based on the absence of TYLCD symptoms, fertility and phenotypical similarity with the cultivated tomato (Figure S2). These lines were used to generate different $F_{2}$ populations (Table 1) (Pérez de Castro et al. 2013). In addition, for the line derived from accession LA1971, respective backcrosses to both parents were generated (Table 1). These $F_{2}$ 
populations and backcross populations were used in this study for genetic mapping. Two of the breeding lines were used for the VIGS experiment: 1538, derived from S. chilense LA1932 and corresponding to line 2 in Pérez de Castro et al. (2013) and 1594, derived from $S$. chilense LA1971 and corresponding to line 5 in Pérez de Castro et al. (2013). Moreover, the line B26, progeny of one homozygous resistant $\mathrm{F}_{2}$ plant (recombinant no. 19 in Table S1) derived from LA1932, was also included in the VIGS experiment (Table 3).

In Florida, four breeding lines with begomovirus resistance derived from different $S$. chilense sources were developed through the University of Florida tomato breeding programme. Resistance to either TYLCV and/or tomato mottle virus was selected phenotypically over multiple seasons. Fla. 8680 (Verlaan et al. 2013) and Fla. 8383 both have resistance derived from accession LA2779. Fla. 8783 is a small-fruited line with resistance from accession LA1932. And Fla. 976 has resistance derived from LA1938. Resistance in each line, with exception of Fla. 8383, was determined previously to co-segregate with a S. chilense introgression on chromosome 6 and spanning the $T y-1 / T y-3$ locus.

\section{TYLCV inoculation}

For TYLCV tests in Wageningen, The Netherlands, an infectious TYLCV-IL clone (pTYCz40a) originating from Israel was used for agro-inoculation using the method as described in Verlaan et al. (2011). Briefly, A. tumefaciens LBA4404 was transformed, cultured in $\mathrm{LB}$, pelleted, and resuspended in infiltration medium at an $\mathrm{OD}_{600}$ of 0.5 . Seeds were sown, and plants were kept under greenhouse conditions at a temperature of $23{ }^{\circ} \mathrm{C}$ and relative humidity of $60 \%$ during a 16-h day/8-h night regime. Three-week-old seedlings were infiltrated by pressure inoculation in the leaves with a needleless syringe. For the VIGS experiments, the agro-infiltration was done 2 weeks after TRV inoculation.

For TYLCV test in Valencia, Spain, whiteflymediated inoculation as previously described by Pérez de Castro et al. (2013) was used. Whiteflies were biotype Q (supplied by F. Beitia, Instituto Valenciano de Investigaciones Agrarias, IVIA, Valencia, Spain) and viruliferous for the Spanish TYLCV isolate TYLCV-MId[ES:72:97] (accession no. AF071228).
This "Mild" isolate also originates from Israel (Fauquet et al. 2008). Both the TYLCV-IL and the TYLCV-Mld[ES:72:97] isolates belong to the same TYLCV viral species. Briefly, plants were inoculated at 3-4 true-leaf stage during 7 days in a climatic chamber inside muslin-covered cages. After this period, plants were transplanted in a greenhouse with controlled temperature until the end of the assay. Symptom severity was scored at 15, 25, 35, 45 and 55 days post inoculation using a scale (Friedmann et al. 1998) from 0 (no visible symptoms) to 4 (very severe symptoms; plants cease to grow) (Figure S3). The limit to classify individual plants as resistant or susceptible was established at symptom score 2, based on previous studies (Pérez de Castro et al. 2007). Plants scored under 2 were considered resistant, given that no significant yield losses were expected as a consequence of infection, while plants scored 2 or higher were considered susceptible.

\section{TRV-based VIGS}

For the silencing experiments, TRV constructs and procedures as described in (Verlaan et al. 2013) were used. Briefly, A. tumefaciens strain GV3101 containing the TRV replicons were cultured, pelleted, and resuspended in infiltration medium. Agro-infiltration was performed on cotyledons of 10-day-old seedlings using pressure inoculation.

RNA isolation and cDNA synthesis

For sequence analysis, 3-week-old seedlings were agro-inoculated as described above. Three weeks after agro-inoculation, top leaves of plants were harvested and grinded in liquid nitrogen using mortar and pestle. Total RNA was extracted by using the RNeasy Plant Mini Kit (Qiagen) as described by the manufacturer. One- $\mu \mathrm{g}$ RNA was digested using DNase I (Amp. Grade) following the manufacturers protocol (Invitrogen), and cDNA was synthesized using the iScript cDNA Synthesis Kit following the protocol (Bio-Rad).

Sequence analysis of the $S$. chilense-derived lines and accessions

For amplifying the region containing the 5 prime deletion, primers Del-F1 (5'-TTCAAGTATATACAGGAAAAATGGGTGATCCG- $3^{\prime}$ ) and Del-R1 
(5'-CTGAGGGCTTGCACAGGCCAAT-3') were used. For amplifying the region containing the catalytic domain, primers DFDGD-F4 (5'GGGCGTGTTTTGGTCTACAG- ${ }^{\prime}$ ) and DFDG-R4 (5'-GCTATCAGCTGCCAGAGACAT-3') were used. PCR amplification was performed according to standard protocols in an Eppendorf Mastercycler Pro. Amplified fragments were sequenced and analysed using SeqMan Pro 9 (DNA Star). Alignments were made with MEGA version 5 (Tamura et al. 2011).

The $R D R$ cDNA sequence from $S$. lycopersicum "Moneymaker" (MM), the $T y-1$ allele from $S$. chilense LA1969 and the Ty-3 allele from $S$. chilense LA2779 were described by Verlaan et al. (2013) and published in Patent No. WO2012125025 \& US2014208459 $($ SEQ1 $=T y-1$; SEQ3 = MM). The $R D R$ cDNA sequence from $S$. peruvianum was obtained from the SGN $S$. peruvianum de novo transcriptome (a19742). Genomic sequences/contigs were available for Solanum lycopersicum M82, S. pimpinellifolium LA1589, S. arcanum LA2157, S. pennellii LA716, S. habrochaites LYC4 (NCBI WGS whole genome shotgun contigs data), S. chilense introgression line Gh13 and S. chilense introgression line BTI-87 (SGN database tomato inbred lines). $R D R$ exons were extracted from the genomic sequence based on homology with the S. lycopersicum "Moneymaker " $R D R$ allele. In the $S$. habrochaites LYC4 genomic sequence, part of the $R D R$ gene was missing, i.e. a large part of intron 8 and exon 9. This was confirmed by PCR analysis and sequencing. RNA was isolated from TYLCV-infected S. chilense LA1932, LA1938, LA1971, G1.1556 and G1.1558, 19 days post-infection. cDNA was prepared, and full-length $R D R$ cDNA sequences were obtained by PCR with primers Ty-F7 and Ty-R5 (Verlaan et al. 2013). Sequences were determined from nested PCR products with primers RDR-F3 + R10, RDR-F7 + R7, RDR-F6 + R4, RDR-F4 + R5 (Figure S4 in Verlaan et al. 2013).

The RDR cDNA sequence from $S$. chilense G1.1556 was smaller than the expected size of approximately $3 \mathrm{~kb}$. Nested PCR with primers RDRF7 and RDR-R7 was not successful. Therefore, exons 9-14 were amplified from genomic DNA, although we could not verify whether they are included in the transcript. The PCR product with primers RDR-F3 and RDR-R10 was larger than the expected 1068 bp and proved to contain intron 17.
De novo assembled wild species genomes and resequencing collection and analysis of the deletion and the catalytic domain

Data of the 84 accessions of the 100 tomato genome resequencing consortium (The 100 Tomato Genome Sequencing Consortium 2014) were obtained from the European Nucleotide Archive (http://www.ebi.ac.uk/ ena/; project PRJEB5235). The de novo assemblies of S. arcanum LA2157, S. habrochaites LYC4, and S. pennellii LA716 were obtained from the same resource and are available under the project numbers PRJEB5226, PRJEB52267 and PRJEB52268, respectively. In short, 84 tomato and related wild species were re-sequenced with a read depth of approximately $42 \times$ (The 100 Tomato Genome Sequencing Consortium 2014). For a list of sequenced species and their variants, we refer to http:// www.tomatogenome.net. Sequence reads were mapped to the reference genome of $S$. lycopersicon cv. Heinz version SL2.40 (The Tomato Genome Consortium 2012) using BWA (Li and Durbin 2009), SNP and INDELS were called using samtools (Li et al. 2009) and saved in the variant call format (VCF) (Danecek et al. 2011). Variants were visually inspected using the Integrative Genomics Viewer (IGV) (Robinson et al. 2011).

Phylogenetic analysis

An unrooted neighbour joining tree was constructed from multiple sequence alignment using MAFFT version 7 (http://mafft.cbrc.jp/alignment/server/).

\section{Quantitative RT-PCR}

For the gene expression experiment, leaf samples of the top part of each plant were taken 0 and 19 days after TYLCV inoculation; the mock treatment consisted of infiltration media without bacteria. Total RNA extraction, cDNA synthesis and quantitative real-time PCR were performed as described in Verlaan et al. (2013). For RT-PCR of Ty-1/ty-1, primers 180-F1 and 180-R2 were used. The actin (ACT) gene was used as reference, using primers ACT-F and ACT$\mathrm{R}$; gene expression levels were calculated using the $\boldsymbol{\Delta} \boldsymbol{\Delta} \mathrm{Ct}$ method (Verlaan et al. 2013).

Acknowledgments The infectious TYLCV clone was kindly provided by Professor Eduardo Rodríguez Bejarano (Universidad de Málaga). We thank Dick Lohuis for his help 
with agro-infiltrations, Marc Hendriks and Marjon Arens for RNA isolation and sequencing. This project was financed by the Centre for BioSystems Genomics (CBSG), which is part of the Netherlands Genomics Initiative/Netherlands Organization for Scientific Research (http://www.cbsg.nl). Olga Julián was granted a scholarship by Generalitat Valenciana.Open Access This article is distributed under the terms of the Creative Commons Attribution 4.0 International License (http://creativecommons.org/licenses/by/4.0/), which permits unrestricted use, distribution, and reproduction in any medium, provided you give appropriate credit to the original author(s) and the source, provide a link to the Creative Commons license, and indicate if changes were made.

\section{References}

Agrama H, Scott J (2006) Quantitative trait loci for tomato yellow leaf curl virus and tomato mottle virus resistance in tomato. J Am Soc Hortic Sci 131:267-272

Anbinder I, Reuveni M, Azari R, Paran I, Nahon S, Shlomo H, Chen L, Lapidot M, Levin I (2009) Molecular dissection of tomato leaf curl virus resistance in tomato line TY172 derived from Solanum peruvianum. Theor Appl Genet 119:519-530

Bai Y, Van der Hulst R, Huang C, Wei L, Stam P, Lindhout P (2004) Mapping Ol-4, a gene conferring resistance to Oidium neolycopersici and originating from Lycopersicon peruvianum LA2172, requires multi-allelic, single-locus markers. Theor Appl Genet 109:1215-1223

Butterbach P, Verlaan MG, Dullemans A, Lohuis D, Visser RGF, Bai Y, Kormelink R (2014) The TYLCV Resistance Gene $T y-1$ confers resistance in tomato through enhanced transcriptional gene silencing. PNAS 111:12942-12947

Cohen S, Lapidot M (2007) Appearance and expansion of TYLCV: a historical point of view. In: Czosnek H (ed) Tomato yellow leaf curl virus disease. Springer, The Netherlands, pp 3-12

Danecek P, Auton A, Abecasis G, Albers CA, Banks E, DePristo MA, Handsaker RE, Lunter G, Marth GT, Sherry ST, McVean G, Durbin R, Group GPA (2011) The variant call format and VCFtools. Bioinformatics 27:2156-2158

Fauquet CM, Briddon RW, Brown JK, Moriones E, Stanley J, Zerbini M, Zhou X (2008) Geminivirus strain demarcation and nomenclature. Arch Virol 153:783-821

Friedmann M, Lapidot M, Cohen S, Pilowsky M (1998) A novel source of resistance to Tomato yellow leaf curl virus exhibiting a symptomless reaction to viral infection. J Am Soc Hortic Sci 123:1004-1007

Hanson PM, Green SK, Kuo G (2006) Ty-2, a gene on chromosome 11 conditioning geminivirus resistance in tomato. Tomato Genet Coop Rep 56:17-18

Hutton SF, Scott JW (2013) Fine-mapping and cloning of $T y-1$ and $T y-3$; and mapping of a new TYLCV resistance locus, "Ty-6". In: Tomato breeders round table proceedings 2013, Chiang Mai, Thailand

Hutton SF, Scott JW, Schuster DJ (2012) Recessive resistance to tomato yellow leaf curl virus from the tomato cultivar tyking is located in the same region as Ty-5 on chromosome 4. HortScience 47:324-327

Ji Y, Schuster DJ, Scott JW (2007) Ty-3, a begomovirus resistance locus near the Tomato yellow leaf curl virus resistance locus $T y-1$ on chromosome 6 of tomato. Mol Breeding 20:271-284

Ji Y, Scott JW, Schuster DJ, Maxwell DP (2009) Molecular mapping of $T y-4$, a new tomato yellow leaf curl virus resistance locus on chromosome 3 of tomato. J Am Soc Hortic Sci 134:281-288

Levin I, Karniel U, Fogel D, Reuveni M, Gelbart D, Evenor D, Chen L, Nahon S, Shlomo H, Machbosh Z, Lapidot M (2013) Cloning and analysis of the tomato yellow leaf curl virus resistance gene Ty-5. In: Tomato breeders round table proceedings 2013, Chiang Mai, Thailand

Li H, Durbin R (2009) Fast and accurate short read alignment with Burrows-Wheeler transform. Bioinformatics 25:1754-1760

Li H, Handsaker B, Wysoker A, Fennell T, Ruan J, Homer N, Marth G, Abecasis G, Durbin R (2009) The sequence alignment/map format and SAMtools. The sequence alignment/map format and SAMtools. Bioinformatics 25:2078-2079

Mejía L, Teni RE, Vidavski F, Czosnek H, Lapidot M, Nakhla MK, Maxwell DP (2005) Evaluation of tomato germplasm and selection of breeding lines for resistance to begomoviruses in Guatemala. In: Momol MT, Ji P, Jones JB (eds) Proceedings 1st international symposium on tomato diseases. Acta Horticult 695:251-256

Menda N, Strickler SR, Edwards JD, Bombarely A, Dunham DM, Martin GB, Mejia L, Hutton SF, Havey MJ, Maxwell DP, Mueller LA (2014) Analysis of wild-species introgressions in tomato inbreds uncovers ancestral origins. BMC Plant Biol 14(1):287

Pérez de Castro A, Díez MJ, Nuez F (2007) Inheritance of Tomato yellow leaf curl virus resistance derived from Solanum pimpinellifolium UPV16991. Plant Dis 91:879-885

Pérez de Castro A, Julián O, Díez M (2013) Genetic control and mapping of Solanum chilense LA1932, LA1960 and LA1971-derived resistance to tomato yellow leaf curl disease. Euphytica 190:203-214

Pico B, Ferriol M, Diez MJ, Nuez F (1999) Developing tomato breeding lines resistant to tomato yellow leaf curl virus. Plant Breeding 118:537-542

Robinson JT, Thorvaldsdottir H, Winckler W, Guttman M, Lander ES, Getz G, Mesirov JP (2011) Integrative genomics viewer. Nature. Biotech 29:24-26

Sahu PP, Puranik S, Khan M, Prasad M (2012) Recent advances in tomato functional genomics: utilization of VIGS. Protoplasma 249(4):1017-1027

Scott JW, Stevens MR, Barten JHM, Thome CR, Polston JE, Schuster DJ, Serra CA (1996) Introgression of resistance to whitefly-transmitted geminiviruses from Lycopersicon chilense to tomato. In: Gerling D, Mayer RT (eds) Bemisia 1995; taxonomy, biology, damage control, and management. Intercept Press, Andover, pp 357-367

Tamura K, Peterson D, Peterson N, Stecher G, Nei M, Kumar S (2011) MEGA5: molecular evolutionary genetics analysis using maximum likelihood, evolutionary distance, and maximum parsimony methods. Mol Biol Evol 28:2731-2739 
The 100 Tomato Genome Sequencing Consortium (2014) Exploring genetic variation in the tomato (Solanum section Lycopersicon) clade by whole-genome sequencing. Plant J 80:136-148

The Tomato Genome Consortium (2012) The tomato genome sequence provides insights into fleshy fruit evolution. Nature 485:635-641

Vanitharani R, Chellappan P, Pita JS, Fauquet CM (2004) Differential roles of $\mathrm{AC} 2$ and $\mathrm{AC} 4$ of cassava geminiviruses in mediating synergism and suppression of posttranscriptional gene silencing. J Virol 78:9487-9498

Verlaan MG, Szinay D, Hutton SF, de Jong H, Kormelink R, Visser RGF, Scott JW, Bai Y (2011) Chromosomal rearrangements between tomato and Solanum chilense hamper mapping and breeding of the TYLCV resistance gene $T y-1$. Plant J 68:1093-1103

Verlaan MG, Hutton SF, Ibrahem RM, Kormelink R, Visser RGF, Scott JW, Edwards JD, Bai Y (2013) The tomato yellow leaf curl virus resistance genes $T y-1$ and $T y-3$ are allelic and code for DFDGD-class RNA-dependent RNA polymerases. PLoS Genet 9(3):e1003399. doi:10.1371/ journal.pgen.1003399

Vidavski F (2007) Exploitation of resistance genes found in wild tomato species to produce resistant cultivars; Pile up of Resistant Genes. In: Czosnek H (ed) Tomato yellow leaf curl virus disease. Springer, Netherlands, pp 363-372

Willmann MR, Endres MW, Cook RT, Gregory BD (2011) The functions of RNA-dependent RNA polymerases in arabidopsis. In: The Arabidopsis Book, e0146

Yang X, Caro M, Hutton SF, Scott JW, Guo Y, Wang X, Rashid MH, Szinay D, de Jong H, Visser RGF, Bai Y, Du Y (2014) Fine mapping of the tomato yellow leaf curl virus resistance gene $T y-2$ on chromosome 11 of tomato. Mol Breeding 34:749-760

Zamir D, Ekstein Michelson I, Zakay Y, Navot N, Zeidan M, Sarfatti M, Eshed Y, Harel E, Pleban T, van Oss H (1994) Mapping and introgression of a tomato yellow leaf curl virus tolerance gene, $T y-1$. Theor Appl Genet 88:141-146 